\title{
Re-envisioning the Museum Experience: Combining New Technology with Social-Networking
}

\author{
Madhuri Koushik, Eun Jung Lee, Laura Pieroni, \\ Emily Sun, and Chun-Wei Yeh \\ Carnegie Mellon University \\ Entertainment Technology Center \\ Silicon Valley Campus, Spring 2010 \\ madhuri.koushik@gmail.com, ejleeart@gmail.com, \\ lpieronieandrew.cmu.edu, emilysuneandrew.cmu.edu, \\ glaciedge@gmail.com
}

Client: California Academy of Sciences

\begin{abstract}
The goal of the project was to design an integrated system for the California Academy of Sciences that combined new technology with a socialnetworking based website to promote educational learning. Five mini-games were developed for the iPad and connected to a series of websites through a database. The use of new technology drew in users that would not have otherwise engaged in the experience. Connecting with a social-networking website opens up many future possible implications for expanding edutainment.
\end{abstract}

Keywords: edutainment, new genres of entertainment technology, socialnetworking, enhanced museum experience.

\section{Introduction}

Museums have been expanding to incorporate technologies that allow visitors a more interactive experience [1]. Interactivity not only further engages users, but also provides the opportunity for continued learning. Museums like the Exploratorium enhanced the museum experience using RFID tags [2]. The San Jose Tech Museum uses barcodes on their admissions tickets so that visitors can view photographs and the activities they participated in on a website at home. More recently, the CooperHewitt, National Design Museum distributed to each museum guest an iPod Touch that provided access to interviews and slideshows relevant to the exhibit. While these museums have used these technologies to further enhance the museum experience, there has not been adequate research into what effect the technologies themselves have in drawing in guests.

At the same time that museums have been expanding their connection to virtual information, a recent surge in social-networking games has connected people through websites. In November of 2009, Facebook-game creation company, Zynga, reached 100 million unique visitors per month. Social-networking games have been especially 
successful because of the inherent sociability, spontaneity, narrativity, and playfulness framework used [3]. While there has been research into the possible use of Facebook for higher educational purposes [4], there has not been focus on creating educational social-networking sites.

Thus far, museums have not capitalized on the success of social-networking sites, nor tested the boundaries of using consumer-hyped technology. The goal of the project was to design an integrated system for the California Academy of Sciences that combined new technology with a social-networking based website to promote educational learning.

\section{Overview of System}

Although the demographic of guests visiting the California Academy of Sciences varied largely, we decided to focus our target demographic to $6^{\text {th }}$ and $7^{\text {th }}$-grade students.

The experience begins when museum visitors create profiles on the California Academy of Sciences website. Initially they are able to personalize a limited number of characteristics of their avatars. Once they visit the museum, they play mini-games on iPad kiosks to accumulate points on their accounts. These points can then be redeemed at home by returning to the California Academy of Sciences website. Accessing the website from home allows the user to further personalize an avatar, learn more facts, and compare their scores on the mini-games and their avatar with those of their peers. Points can be redeemed to upgrade the avatar's available attributes and uniforms. The general system architecture can be seen in Fig. 1.

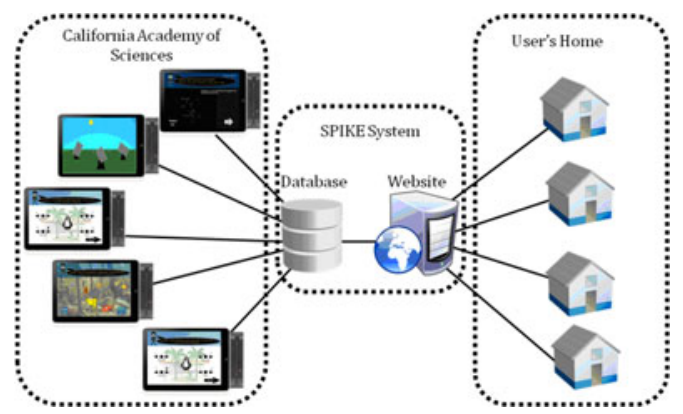

Fig. 1. System architecture connecting data collected from the mini-games in the Academy to the website accessible from home

\subsection{Mini-Games}

We created five mini-games and developed them for the iPad. The release date of the iPad was April 3, 2010, and the opening of our project was scheduled for April 22, 2010. Based on the popularity and demand for previous Apple products, we anticipated that releasing our games on the iPad, a new technology, would increase the interest in our product. We also wanted to take advantage of the iPad functions, like the accelerometer, that would increase the interactivity of our games. 
The five games were placed in relevant areas of the California Academy of Sciences and contained educational material inherent in the games. For the game in the Aquarium, museum guests were presented with a variety of photographs of camouflaged animals and had to tap the animal before time ran out. The name and a fact about each animal were displayed.

In the African Hall mini-game, guests get the opportunity to design their own penguin by altering its height, weight, fin length, and color and see how it fared in the South African wild. Penguins could either be eaten by a shark, drown, or survive. The purpose of this game was to educate students about the difficulties that penguins face every day.

The Altered State Exhibit had guests tap the iPad to move the character to collect the garbage. Tilting the iPad shifted the garbage to allow for easier collection. More points were awarded for collecting toxic waste.

After watching the Planetarium show, guests were invited to test their knowledge of the constellations by finding them in photographs of the night sky. Each game would give the guest the opportunity to find one of six constellations after briefly being shown the constellation (see Fig. 2).

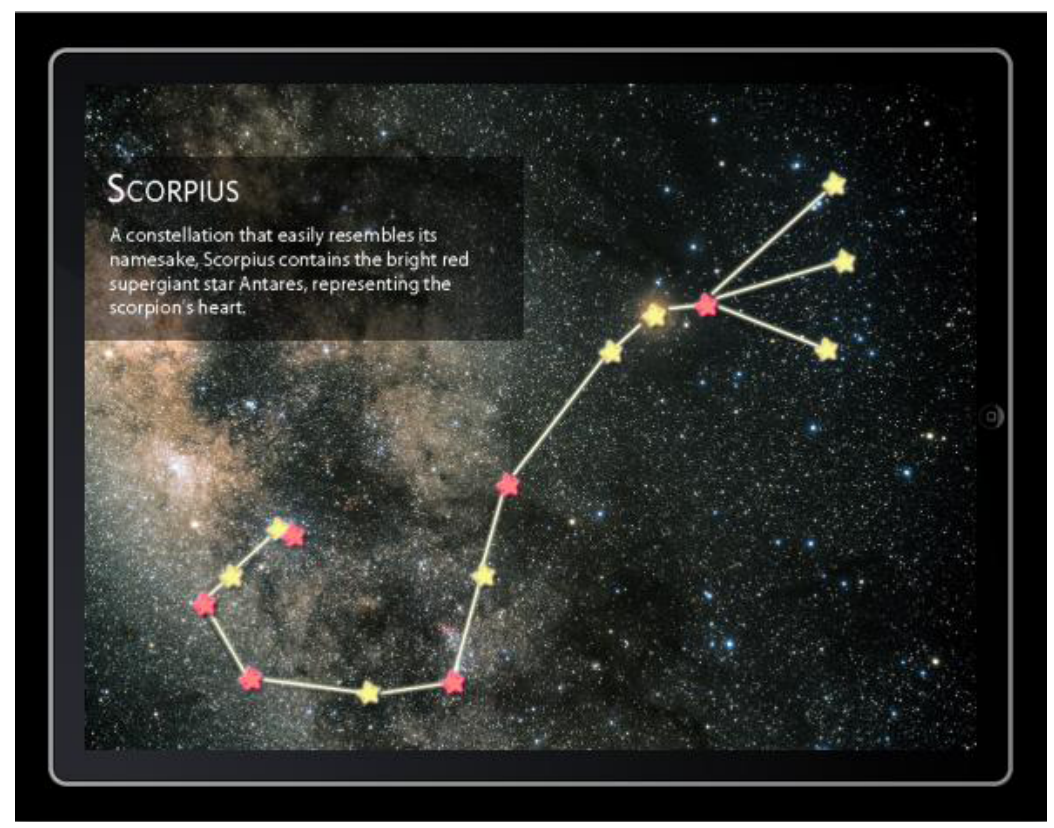

Fig. 2. Example of constellation game and educational fact

Guests guided the blue morpho butterfly in the Rainforest game. By tilting the iPad, users controlled the butterfly's height and had to avoid the arowana fish as well as the silver-beaked tanager bird. They gained extra points by collecting fruit along the way.

At the end of each of the games, the total points and a "did you know" fact were displayed. 


\subsection{Social-Networking Website}

Fundamental to many social-networking games is the creation of the personal identity that represents the user in the virtual world. For the avatars for the social-networking aspect of our project, we had users create their own personal explorer that could have different science-related occupations such as diver and botanist (see Fig. 3). Users redeemed their points from the iPad games to unlock outfits and other attributes for their explorers.

To enforce the connection between the website and the mini-games, a different explorer appeared in each of the mini-games in the California Academy of Sciences. Also, the discover tab was divided into the different areas of the museum where the iPads were located. Within each tab, users were able to find more information relating to the exhibit.

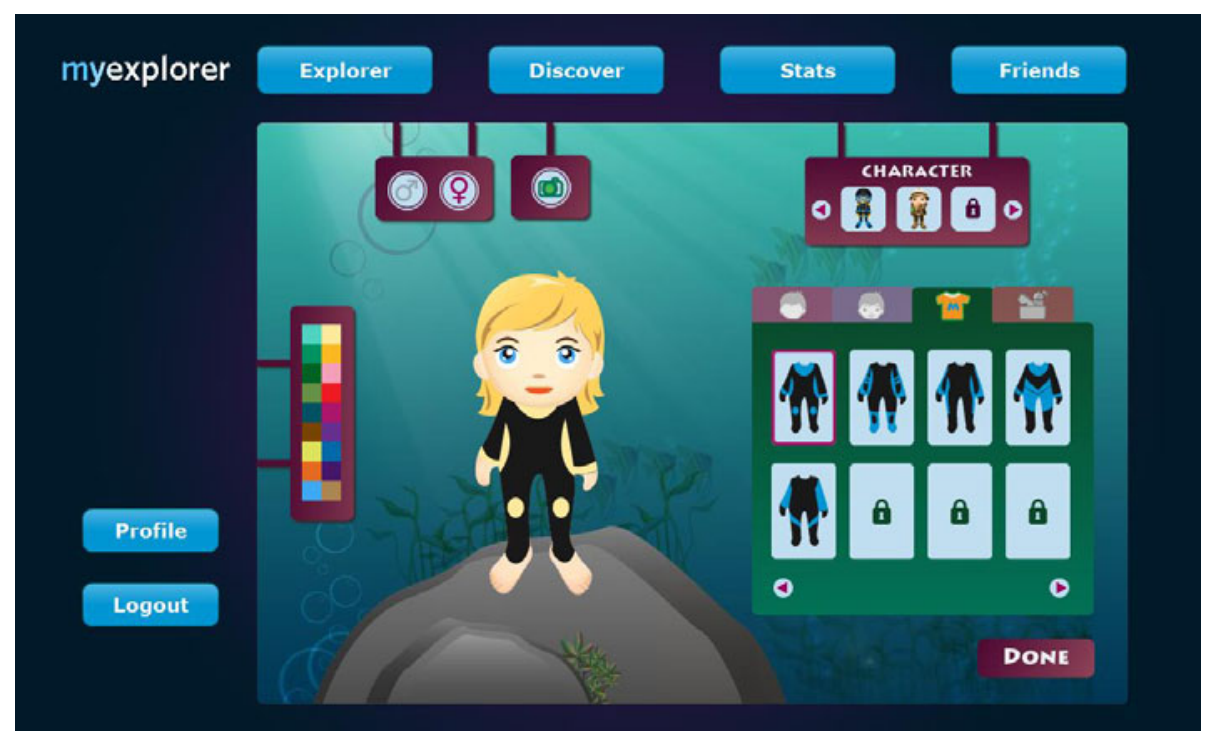

Fig. 3. Screenshot of avatar creation portion of social-networking website

On the website, users were able to add their friends and compare their explorers with those of their peers. The "Stats" tab showed the names and explorers of the users with the top three highest scores on each of the iPad games, as well as the user's highest score and rank on each of the games.

\section{User Response}

User testing was conducted at a school on 50 students ranging from fourth to eight grade. Students were brought in groups of five and each played a different game on the iPad (see Fig. 4). $72 \%$ of the students said they would be interested in redeeming their points online. They also had the opportunity to write a fact that they learned 
from the game. $67 \%$ of students that played the camouflage game $(n=12)$ were able to state a fact that they learned from the game. Example responses to this prompt for all the games include "I learned to make your penguin black or it will be eaten by a shark," "the bird is the enemy of the butterfly," and "animals, such as lizards, camouflage themselves."

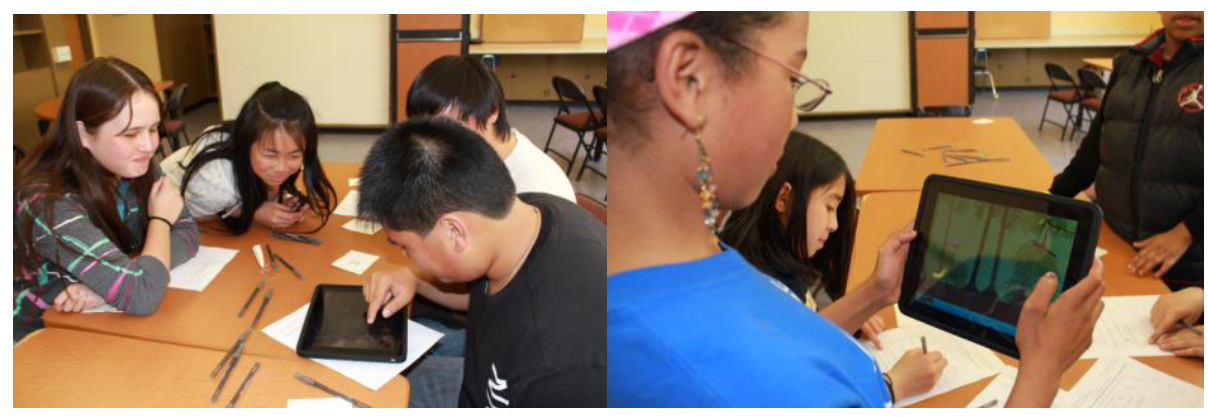

Fig. 4. Photographs from playtesting session at school

From our opening on April 22, 2010, we had over 300 museum guests play with the iPad games (see Fig. 5). At both the user testing session as well as opening, much of the excitement came from the fact that they were getting to use a new technology. Many museum visitors would play the game based on the sole desire to try out the iPad.

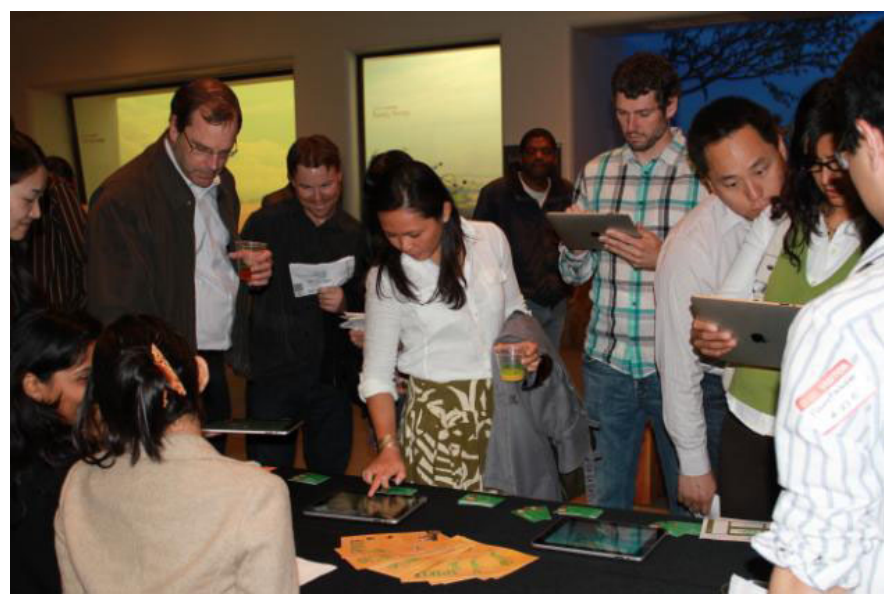

Fig. 5. Photograph from the opening at the California Academy of Sciences

While it is unreasonable to expect museums to pour their resources into always maintaining the most current technological inventions, capitalizing on the opportunity to develop on commercially hyped technology could jumpstart interest. For something 
like a socially-networked website, the most difficult part is getting users to initially engage and create a profile. Users are more inclined to join a website that already has a wide following and even more so if their friends are already playing on the website. Once users have spent time and effort on the site, they are more likely to return. Utilizing new technologies is an opportunity to increase the number of initial users that create profiles on a new social-networking game website.

\section{Conclusion}

This project combined the use of mini-games on iPads in the California Academy of Sciences with a social-networking website to create an engaging, educational experience. There is much more research that can be done to determine the extent of the educational effect of a system like this. For example, how might the experience of learning at the museum, enforcing that learning at home, and repeating through return visits to the website affect retention of facts? As interactive devices and socialnetworking gaming continue to expand, museums should take advantage of the technology as an opportunity to further educate visitors. It is our hope that this research spurs discussion on the value of educational research in museums and the.

Acknowledgments. This work was sponsored by the California Academy of Sciences.

\section{References}

1. Martin, J., Trummer, C.: Personalized multimedia information system for museums and exhibitions. In: Maybury, M., Stock, O., Wahlster, W. (eds.) INTETAIN 2005. LNCS (LNAI), vol. 3814, pp. 332-335. Springer, Heidelberg (2005)

2. His, S., Fait, H.: RFID enhances visitors' museum experience at the Exploratorium. Communications of the ACM (48), 60-65 (2005)

3. Jarvinen, A.: Game design for social networks: interaction design for playful dispositions. In: ACM SIGGRAPH Symposium on Video Games, pp. 95-102. ACM, New York (2009)

4. Mason, R., Rennie, F.: E-learning and social networking handbook: resources for higher education. Routledge, New York (2008) 